\title{
As mudanças e dificuldades na vivência acadêmica em meio à pandemia da COVID-
} 19: relato de experiência

\section{The changes and difficulties in the academic experience amidst the pandemic of COVID-19: experience report}

\author{
Thuany Montes de Almeida \\ Instituição: Centro Universitário FAMINAS (UNIFAMINAS), Muriaé-MG. \\ Thaís Praxedes Rodrigues \\ Instituição: Centro Universitário FAMINAS (UNIFAMINAS), Muriaé-MG. \\ Wanda Ticiane Pires de Castro \\ Instituição: Centro Universitário FAMINAS (UNIFAMINAS), Muriaé-MG. \\ Bruno Gonçalves Machado \\ Instituição: Centro Universitário FAMINAS (UNIFAMINAS), Muriaé-MG. \\ Pascale Gonçalves Massena \\ Instituição: Centro Universitário FAMINAS (UNIFAMINAS), Muriaé-MG.
}

\section{RESUMO}

Desde que a doença COVID-19 foi declarada como pandemia, essa transformou os hábitos de vida da população global em várias esferas. Dessa forma, o presente artigo traz a perspectiva de quatro acadêmicos da área de saúde, a fim de relatar a experiência de aprendizado por ensino remoto.

Palavras-chave: Ensino online, Pandemia, Estudantes de Ciências da Saúde.

\section{ABSTRACT}

Since the disease COVID-19 was declared a pandemic, it has transformed the life habits of the global population in several spheres. Thus, this article brings the perspective of four health science students, in order to report the experience of learning by remote teaching.

Keywords: Online Teaching, Pandemic, Health Sciences Students.

\section{INTRODUÇÃO}

Em dezembro de 2019, na cidade de Wuhan, na China, foi identificada pela primeira vez a doença provocada pelo vírus Sars-Cov-2 (COVID-19) e em 11 de março de 2020, de acordo com a Organização Mundial da Saúde (OMS), foi declarada como pandemia. Diante disso, em março de 2020, o Ministério da Educação (MEC) divulgou a Portaria de n 343/2020, que “dispõe sobre a substituição das aulas presenciais por aulas em meios digitais enquanto durar a situação de pandemia do Novo Coronavírus - COVID-19”. Assim, as instituições de ensino se viram obrigadas a adotar o método de ensino online, além de tentar 
minimizar os impactos negativos sobre a educação dos alunos (MAIA BR e DIAS PC, 2020; BRASIL, 2020).

Com os métodos adotados de contenção do vírus, como o isolamento social, além da formação acadêmica ser afetada, a saúde mental da população também fica atingida, uma vez que, o conceito de boa saúde mental está relacionado ao bom relacionamento do indivíduo com seu ambiente. Sendo assim, a partir do novo contexto de pandemia, ocorreram grandes modificações na vida de toda população, o que exigiu grandes adaptações para lidar com a nova realidade enfrentada (RODRIGUES JVS e LINS ACAA, 2020).

\section{OBJETIVO}

Relatar, de forma geral, a experiência dos estudantes de ciências da saúde frente ao novo modelo de ensino proposto pelas instituições em meio a pandemia do novo coronavírus e os impactos gerados aos mesmos.

\section{RELATO DE EXPERIÊNCIA}

Com a quebra abrupta, ocasionada pela pandemia do Coronavírus, na rotina do estudante da área de saúde, as incertezas, medos e angústias do meio externo e interno do indivíduo se tornaram uma avalanche devido a série de novas informações. Dessa forma, todos tiveram que se adaptar ao "novo normal”, gerando para os estudantes, em específico, impactos no que tange a vivência acadêmica e seus efeitos psicológicos, físicos e sociais.

A rotina, embora queira imitar os moldes das aulas presenciais, é mais cansativa e prolonga-se para além do tempo que seria normalmente dedicado à vida acadêmica, posto que o ambiente de estudos e familiar, se misturam, levando a uma perda em ambos. Assim, o convívio social se torna ainda mais restrito por conta das obrigações, ocasionando uma piora dos fatores psicológicos, o que torna a experiência do ensino remoto mais difícil e por vezes, solitária.

Fisicamente, os desgastes do "home office" também são observáveis, que devido ao tempo estendido em frente aos dispositivos eletrônicos, o corpo sofre duros impactos, culminando em cefaleia e dores do sistema locomotor, por exemplo. Além disso, as limitações às ações ao ar livre, como as atividades físicas e lazer, contribuem para o aumento do sedentarismo e estresse.

Deve-se, ainda, ressaltar o processo adaptativo às novas tecnologias necessárias para acesso ao conteúdo letivo, exigindo tanto de docentes como de discentes resiliência, seja para aprender a lidar com as ferramentas virtuais ou para contornar os problemas técnicos, que se destacam à maior dependência desse meio, além da acessibilidade à internet ou a equipamentos, cuja qualidade contorna o poder aquisitivo do aluno. 
Outrossim, não se pode negligenciar a possível nocividade curricular, haja visto que a maior parte das atividades extracurriculares como pesquisa, estágios, projetos de extensão, ficaram estacionadas, dado que, comumente, necessitam de um desenvolvimento presencial.

Figura 1 - Estudante de medicina em estudo via remota, devido à pandemia da COVID-19, pensando no tão sonhado CRM, no qual poderá ser postergado.

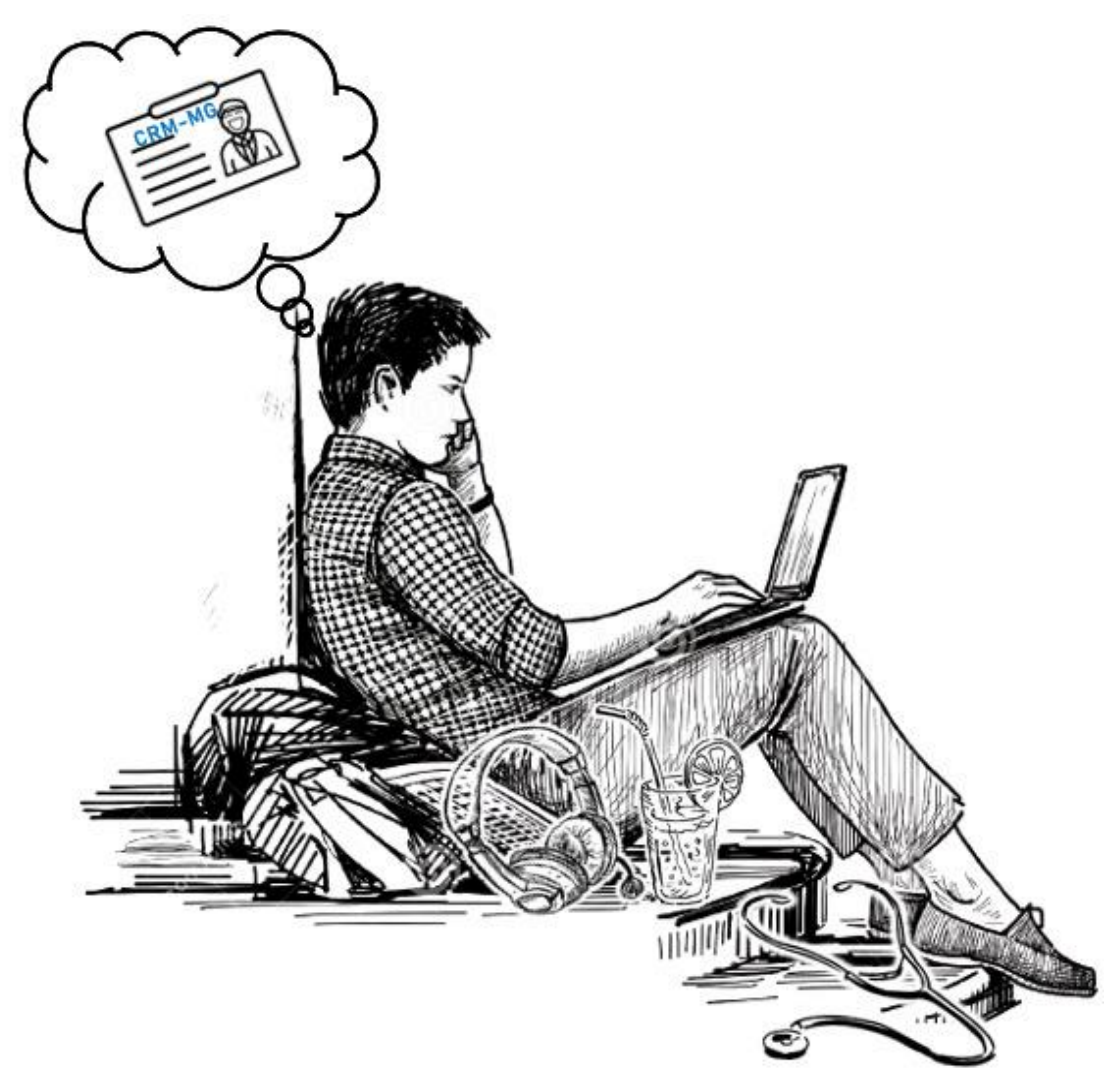

Fonte: MONTES TA, et al., 2021.

\section{DISCUSSÃO}

Mediante ao ensejo citado, em que o MEC permitiu a substituição das aulas presenciais por aulas na modalidade remota, pensa-se, então, sobre a finalidade da vivência acadêmica, isto é, a formação de um profissional apto e qualificado para agir na área de escolha e em quanto a transferência das atividades acadêmicas para o ambiente virtual, comum a várias instituições de ensino superior, pode comprometer esse fator de suma importância. Apesar das inúmeras dificuldades inerentes ao cenário pandêmico, é de comum acordo que ele será transformador, tendo em vista que acelerou a incorporação de novas tecnologias e a quebra de moldes (CASTAMAN AS e RODRIGUES RA, 2020). 


\section{CONSIDERAÇÕES FINAIS}

O fechamento de instituições de ensino, em decorrência da pandemia de COVID-19, levou a todos os indivíduos que se relacionam ao meio educacional a um futuro imprevisível. No presente trabalho se expôs as experiências e percepções de estudantes do ensino superior na área da saúde, sendo a resiliência fator determinante para lidar com as incertezas e dificuldades de tal época, que já demonstra impactos psicológicos, físicos, sociais e no processo de aprendizagem.

\section{REFERENCIAS}

1. BRASIL. Diário Oficial da União. 2020. Disponível em: https://www.in.gov.br/en/web/dou/-/portarian-343-de-17-de-marco-de-2020-248564376. Acessado em: 06 de março de 2021.

2. CAVALCANTE ASP, et al. Educação superior em saúde: a educação a distância em meio à crise do novo coronavírus no Brasil. Revista Avances en Enfermería, 2020; 38(1): 113-121.

3. CASTAMAN AS, RODRIGUES RA. Educação a Distância na crise COVID-19: um relato de experiência. Revista Research, society and development, 2020; 9(6): e180963699.

4. FERREIRA GSM, et al. Pandemia da COVID-19 possibilitando a ressignificação das atividades de gestão no ensino superior: relato de experiência. Revista Enfermagem Atual, 2020; 93: e02006.

5. MAIA BR, DIAS PC. Ansiedade, depressão e estresse em estudantes universitários: o impacto da COVID-19. Revista Estudos de Psicologia (Campinas), 2020; 37: e200067.

6. OLIVEIRA SMC, et al. Educação médica: PJTC- Uma escolha na vida acadêmica e as reflexões do impacto da COVID-19 na formação médica. Revista Extensão, 2020; 4(1): 112-119.

7. RODRIGUES JVS, LINS ACAA. Possible impacts caused by the COVID-19 pandemic on children's mental health and the role of parents in this scenario. Revista Research, society and development, 2020; 9(8): e793986533. 